\title{
Application of capillary electrophoresis interfaced to double focusing sector field ICP-MS for nuclide abundance determination of lanthanides produced via spallation reactions in an irradiated tantalum target $\uparrow$
}

\author{
Jason A. Day, ${ }^{a}$ Joseph A. Caruso, ${ }^{* a}$ J. Sabine Becker $^{b}$ and Hans-Joachim Dietze ${ }^{b}$ \\ ${ }^{a}$ Department of Chemistry, University of Cincinnati, Cincinnati OH 45221-0172, USA \\ ${ }^{b}$ Zentralabteilung für Chemische Analysen, Forschungszentrum Jülich GmbH, D-52425 \\ Jülich, Germany
}

Received 3rd April 2000, Accepted 27th June 2000

First published as an Advance Article on the web 10th August 2000

\begin{abstract}
An analytical procedure was developed using capillary electrophoresis (CE) coupled on-line to a doublefocusing sector field inductively coupled plasma mass spectrometer (DF-ICP-MS) for the analysis of mixtures of lanthanide elements in aqueous samples with natural isotope abundances and in a sample taken from an irradiated tantalum target containing artificial nuclide abundances. A MicroMist AR30-1-F02 nebulizer with a Cinnabar small volume cyclonic spray chamber was used for ICP-MS sample introduction. The CE-ICP-MS interface featured a self-aspirating electrolyte make-up solution for electrical ground connection and control of nebulizer suction. The CE-ICP-MS method features fast run times and small sample sizes $(\approx 35 \mathrm{~nL}$ injection volume). Detection limits for the most abundant lanthanide isotopes were $0.72 \mathrm{ppb}$ to $3.9 \mathrm{ppb}$, an improvement of as much as one order of magnitude compared to a quadrupole ICP-MS system using a similar experimental arrangement. Abundances of the most abundant isotopes of lanthanides were found to be within $0.1-2 \%$ of table values for natural samples while isotopes present in smaller amounts were within 3-5\% of table values. The method was applied to samples taken from a tantalum material which was exposed to a high energy proton beam for the production of neutrons via spallation reactions. A large fraction of the spallation products were lanthanides containing nuclide abundances unlike natural samples. Thus, a chemical separation step prior to ICP-MS detection was required to avoid isobaric interferences for the accurate determination of nuclide abundances in such samples. The results of the nuclide abundance determinations were compared to theoretical calculations.
\end{abstract}

\section{Introduction}

A modern approach to the production of high power neutron beams is by spallation reactions with a heavy metal target and a highly energetic proton beam $(\approx 800 \mathrm{MeV})$. Such neutron beams may be used in fundamental and applied investigations in a number of fields including physics, chemistry, biotechnology, engineering and materials science. Thus, as part of a program for the development of such neutron sources, a tantalum target material was irradiated with a high energy proton beam for 500 days at the Rutherford Appleton Laboratory (RAL) in Didcot, UK. Details of the experiments with the tantalum target irradiation may be found elsewhere. ${ }^{1-3}$ Numerous spallation products are present in the irradiated material including nuclides of lanthanide elements containing different abundances from those found in natural samples in the low $\mu \mathrm{g} \mathrm{ml}^{-1}$-low $\mathrm{ng} \mathrm{ml}^{-1}$ concentration range. Theoretical calculations based on HERMES (high energy radiation Monte Carlo elaborate system) and HETC (high energy transport code) have been used to estimate the yields and the distribution of the spallation products. ${ }^{1}$ Some spallation products are stable nuclides, but many are radioactive. Therefore, nuclide abundance and concentration information is needed to assess such samples for storage and handling purposes.

Inductively coupled plasma mass spectrometry (ICP-MS) is a suitable method for the analysis of lanthanides due to its

†Presented in part as poster No. 558 at the 1999 Federation of Analytical Chemistry and Spectroscopy Societies (FACSS) Conference, Vancouver, Canada, October 24-29, 1999. speed, selectivity and sensitivity. However, ICP-MS methods typically utilize known isotopic ratios to correct for isobaric and/or polyatomic interferences which occur when analyzing a mixture of elements. Because nuclide abundances for the lanthanides in the samples taken from the irradiated tantalum target are unnatural, isobaric and polyatomic interferences may not be corrected for in this manner. High resolution mass spectrometric techniques such as double focusing sector field ICP-MS (DF-ICP-MS) may be used to resolve polyatomic interferences of lanthanides, but a resolving power of greater than 10000 is required for the resolution of isobars of lanthanides. This resolving power is not yet attainable in ICP-MS instruments, and, as an added consideration, sensitivity is sacrificed in high resolution mode. ${ }^{4,5}$ Thus, for sensitive and accurate determination of nuclide abundances in such samples, a chemical separation step is required prior to ICPMS detection.

Capillary electrophoresis (CE) is a suitable separation technique in which solvated ions in an electrolyte solution are separated according to their mobilities in solution while subjected to an electric field. The major advantages of $\mathrm{CE}$ separation include fast analysis times, reduced solvent and chemical usage, minute sample volumes, low cost $\mathrm{CE}$ capillaries and high separation efficiencies. The standard method of detection is by on-column direct or indirect UV absorbance detection, but many applications require higher detection sensitivity and selectivity than is achievable in "normal" CE mode. One possibility for improving CE detection sensitivity and also acquiring multielement mass spectrum information is by on-line coupling to ICP-MS. The 
success of interfacing other separation techniques, such as high performance liquid chromatography (HPLC), ${ }^{6,7}$ gas chromatography, ${ }^{8,9}$ and supercritical fluid chromatography, ${ }^{10,11}$ suggests that the CE-ICP-MS coupling should be straightforward, but combining the two techniques is challenging in practice. The two main problems associated with interfacing CE with ICP-MS are maintaining a stable electrical connection to the detection end of the CE capillary and controlling laminar flow caused by the nebulizer gas flow. These considerations are most commonly addressed by the introduction of a conductive sheath flow (make-up) electrolyte around the end of the CE capillary. ${ }^{12-17}$ In the present work, a self aspirating make-up electrolyte is utilized instead of a pump for delivery of make-up electrolyte. $^{18-21}$

Lanthanides are similar in size and chemical properties which makes them a challenge to separate. CE separation of lanthanides has been achieved using a hydroxyisobutyric acid (HIBA) complexing electrolyte solution in which HIBA selectively complexes with the lanthanides and the separation is based on the extent of complexation for each element. ${ }^{22,23}$ Sutton and coworkers ${ }^{14}$ have used this method for CE -ICP-MS in which the make-up electrolyte was delivered to a stainless-steel interface via an HPLC pump for controlling nebulizer suction and to maintain electrical earthing at the end of the capillary near the nebulizer. Indirect UV absorbance detection was directly compared to ICPMS detection, and CE limits of detection were improved by three orders of magnitude using quadrupole ICP-MS detection (ICPQMS) compared to the UV method. The lanthanide spallation products in the tantalum target material are suitable for such a CE separation. The tantalum target samples analyzed in this paper were previously analyzed by HPLC-DF-ICP-MS and nuclide abundances and concentrations were determined., ${ }^{2,3}$ The HPLC method featured separation of all lanthanides in almost 45 min using both anion and cation exchange HPLC. Detection limits for the lanthanide elements ranged from $1.2-0.08 \mathrm{ng} \mathrm{ml}^{-1}$ using a $10 \mu \mathrm{l}$ injection volume. A similar HPLC method may be used in the analysis of fission products. ${ }^{24}$

This paper reports the use of CE-DF-ICP-MS for analysis of lanthanide elements in natural samples and in an irradiated tantalum target material. The CE separation method offers advantages of short analysis time ( $<15 \mathrm{~min})$ and small sample amounts of $\approx 35 \mathrm{~nL}$, thereby reducing ICPMS contamination. The rapid scanning capability of the DFICP-MS allows each nominal mass between 139 and 176 to be monitored versus time, which is an advantage over quadrupole-based mass spectrometers. The CE-ICP-MS peak areas for isotopes of lanthanides are used to calculate isotope ratios and oxide formation rates in samples containing lanthanides with natural isotope abundances and to calculate nuclide abundances of spallation nuclides in an irradiated tantalum target sample.

\section{Experimental}

\section{Instrumentation}

A DF-ICP-MS instrument (Element, Finnigan MAT, Bremen, Germany) was used for all mass spectrometric determinations. ICP-MS operating conditions and data acquisition settings in the instrument operation software (version 1.7) are shown in Table 1. The data acquisition program was set to achieve the fastest scanning rate over the mass range analyzed. One magnet rest with the appropriate settling time was set in the middle of the scanning range to minimize hysteresis. Electrical scanning was used to rapidly acquire ion intensities at each mass. The nebulizer gas and ICP-MS conditions were optimized by introducing a solution of $\mathrm{La}, \mathrm{Tb}$ and $\mathrm{Tm}\left(1 \mathrm{ng} \mathrm{ml}^{-1}\right.$ each) via the self-aspirating CE interface. The ICP rf forward power was adjusted with respect to the ${ }^{139} \mathrm{La}^{+}$signal to minimize oxide formation. The Finnigan guard electrode was used for all ICP-
MS measurements. The CE separation conditions are shown in Table 2 using a Waters Quanta 4000 capillary ion analysis system (Waters Corporation, Milford, MA, USA). CE-ICP MS peak areas and spreadsheet calculations were made using Excel 97 and GRAMS 32 version 5.0 with a chromatography pack (Galactic Software, Salem, NH, USA).

\section{CE conditions and interface}

The CE-ICP-MS schematic including the interface (enlarged) is shown in Fig. 1. The interface components are PEEK tubing, PEEK finger tight fittings and a PEEK four way tee union (Upchurch Scientific, Oak Harbor, WA, USA). The design is based on a commonly reported model from Sutton. ${ }^{15}$ Orange PEEK tubing $(0.50 \mathrm{~mm}$ id $\times 1.6 \mathrm{~mm}$ od $)$ was used as a sleeve around the CE capillary into the four way tee union. The makeup electrolyte was aspirated through a $20 \mathrm{~cm}$ length of Teflon tubing $(1.0 \mathrm{~mm}$ id $\times 1.6 \mathrm{~mm}$ od). The $0.50 \mathrm{~mm}$ platinum interface electrode was sealed via a PEEK sleeve (orange $=0.50 \mathrm{~mm}$ id $\times 1.6 \mathrm{~mm}$ od). The CE capillary was transferred to the nebulizer via green PEEK tubing $(0.76 \mathrm{~mm}$ id $1.6 \mathrm{~mm}$ od) and sealed inside the back of nebulizer via a $1.5 \mathrm{~cm}$ length of Tygon peristaltic pump tubing. All fittings should provide air-tight seals as slight leaks adversely affect the self aspiration of the nebulizer, and thus the CE results. The electrical connection from the grounded electrode in the CE instrument to the platinum electrode in the interface was accomplished by a copper wire fitted with alligator clips. The CE separation conditions were optimized by performing indirect UV analysis of a $100 \mu \mathrm{g} \mathrm{ml}^{-1}$ mixture of lanthanides prepared from standards. An $x-y$ analog chart recorder was used for data acquisition during preliminary investigations. All CE solutions were degassed and filtered prior to use. New capillaries were conditioned by purging with $0.1 \mathrm{M} \mathrm{HCl}$ for $5 \mathrm{~min}, 0.1 \mathrm{M} \mathrm{NaOH}$ for $5 \mathrm{~min}$, and fresh $\mathrm{CE}$ electrolyte for 5 min using the purge option in the CE instrument. When interfaced to ICP-MS, capillary conditioning was performed by hand using Luer lock syringes (Becton Dickinson, Franklin Lakes, NJ, USA) adapted to the capillary via a PEEK sleeve and fittings. Each new CE capillary or fresh electrolyte solution was tested for consistent performance using indirect UV absorbance detection prior to coupling to ICP-MS. Both ends of the CE capillary were made level to prevent a hydrostatic imbalance (siphoning) when interfaced to the ICP-MS.

\section{Chemicals and sample preparation}

Suprapur $\mathrm{HNO}_{3}, \mathrm{HCl}, \mathrm{NaOH}$ and $\mathrm{HIBA}$ were obtained from Merck (Darmstadt, Germany). Milli-Q plus deionized water (18 M $\Omega$ ) was used for all solution preparation and dilutions. The CE electrolyte used was a $6 \mathrm{mM} \alpha$-hydroxyisobutyric acid (HIBA) complexing electrolyte (Fluka, Neu-Ulm, Germany) with 5 mM CIA-Pak UV Cat 1 chromophore (Waters) adjusted to $\mathrm{pH}=4.3$ with $0.1 \mathrm{M} \mathrm{HCl}$. Lanthanide standards with natural isotope ratios were prepared by dissolving chloride salts of each element in Milli-Q plus deionized water. Lanthanide chloride compounds were purchased from Aldrich (Deisenhofen, Germany). For the irradiated tantalum target samples which are highly radioactive, sample preparation was performed in a hot cell. Small chips ( $\approx 50 \mathrm{mg}$ ) of the tantalum material were dissolved in a mixture of concentrated nitric and hydrofluoric acid. The digested solution was then diluted with highly purified water until the dose rate was 50 mREM. ${ }^{1}$ To minimize radioactive ${ }^{182} \mathrm{Ta}$ contamination of the ICP-MS, tantalum was nearly quantitatively $(99.9 \%)$ removed by extraction with tetrahexylammonium bromide in methyl isobutylketone (MIBK). ${ }^{25}$ Hydrofluoric acid from the samples was removed by taking $2.0 \mathrm{ml}$ of the aqueous solution from the extraction procedure and evaporating to near dryness by passing a slight argon stream over the sample for $4 \mathrm{~h}$. The 
Table 1 Operating conditions and data acquisition parameters for ICP-MS measurements

\begin{tabular}{ll}
\hline Forward rf power & $850 \mathrm{~W}$ (with guard electrode) \\
Argon gas flows $/ \mathrm{L} \mathrm{min}^{-1}$ & Cool=14; Auxiliary=0.8; Nebulizer $=0.85$ \\
Nebulizer type & MicroMist AR30-1-F02 (liquid uptake rate $200 \mu \mathrm{l}$ min ${ }^{-1}$ ) \\
Spray chamber & Cinnabar low volume cyclonic \\
Mass resolution & $300 \mathrm{~m} / \Delta m$ \\
Mass range of scan & $80 \%$ peak width for each mass $139-180$ amu \\
Optimization & Maximum ion intensity for $1 \mathrm{ng} \mathrm{m}^{-1139} \mathrm{La}^{+},{ }^{159} \mathrm{~Tb}^{+},{ }^{169} \mathrm{Tm}^{+}$ \\
\hline
\end{tabular}

Table 2 CE operating conditions

\begin{tabular}{|c|c|}
\hline $\mathrm{CE}$ instrument & Waters Quanta 4000 Capillary Ion Analyzer \\
\hline Power supply & Positive $25 \mathrm{kV}$ \\
\hline UV Detection & Indirect at $214 \mathrm{~nm}$ \\
\hline Injection & $30 \mathrm{~s}$ hydrostatic ( $\approx 35 \mathrm{nl}$ injection volume) \\
\hline Capillary & id $75 \mu \mathrm{m} ;$ od $365 \mu \mathrm{m} ; 75 \mathrm{~cm}$ long \\
\hline Electrolyte solution & $6 \mathrm{mM}$ HIBA, $5 \mathrm{mM}$ UV Cat $1, \mathrm{pH}=4.3$ with dilute $\mathrm{HCl}$ \\
\hline ICP-MS make-up buffer & $0.005 \% \mathrm{HNO}_{3}$ \\
\hline Temperature & $22^{\circ} \mathrm{C}$ \\
\hline
\end{tabular}

sample was then constituted in $500 \mu \mathrm{L}$ of Milli-Q plus $18 \mathrm{M} \Omega$ water for analysis.

\section{Results and discussion}

An interface constructed from a stainless-steel union and tube ${ }^{15,17}$ was investigated in preliminary studies. ICP-MS backgrounds were unacceptable (above 5000 counts s$^{-1}$ ) using this interface, most probably due to the make-up electrolyte solution leaching metal from surfaces whilst passing through the tubing and tee junction. To minimize ICP-MS contamination and lower background signals, parts in the interface were constructed of PEEK and a copper wire was used for the high voltage connection in the interface. This design reduced the surface area of metal exposed to the make-up electrolyte and minimized the metal ion contamination from the electrode material. The normal CE current of $4.5 \mu \mathrm{A}$ was maintained with this interface design. The make-up electrolyte solution was a $0.005 \% \mathrm{HNO}_{3}$ solution, which reduced the amount of HIBA and UV Cat-1 reagent to the ICP, and minimized salt or carbon deposits on the sampler and or skimmer cones. This solution displayed acceptable conductance and much lower ICP-MS background signals than the CE electrolyte solution (run buffer). One concern using this make-up solution was that the $\mathrm{pH}$ of the make-up solution was lower than the running electrolyte ( $\mathrm{pH} 2$ versus $\mathrm{pH} 4.5)$ creating isotachophoretic conditions. ${ }^{26}$ Such a $\mathrm{pH}$ gradient across the capillary may affect the electroosmotic flow and induce non-uniform flow, resulting in $\mathrm{CE}$ peak broadening. The resulting electropherograms showed all peaks were baseline-resolved with minimal broadening effects. In fact, the peak widths with the dilute acid make-up electrolyte appeared similar to peak widths observed with the HIBA make-up electrolyte. Therefore, the dilute $\mathrm{HNO}_{3}$ make-up electrolyte was used for all experiments due to the low background signals and otherwise acceptable CE performance.

Table 3 Comparison of three CE detection methods (ICP-quadrupole MS, DF-ICP-MS, and indirect UV absorbance). Method limits of detection $(3 \sigma)$ for lanthanides with $98 \%$ or higher nuclide abundances

\begin{tabular}{llll}
\hline \multicolumn{1}{c}{$\begin{array}{l}\text { ICP-QMS } \\
\text { VG PQ }\end{array}$} & $\begin{array}{c}\text { ICP-DF-MS } \\
\text { Isotope II STE/ng ml }\end{array}$ & $\begin{array}{l}\text { CE-indirect } \\
\text { UV absorbance }\end{array}$ \\
Finnigan Element $/ \mathrm{ng} \mathrm{ml}^{-1} @ 254 \mathrm{~nm}^{-1} \mathrm{ng} \mathrm{ml}^{-1}$
\end{tabular}

\section{Optimization of interface conditions}

Migration times from electropherograms using CE-indirect UV detection were used for comparison of migration times for ICP-MS detection. An equivalent length of CE capillary was used for all ICP-MS studies. ${ }^{21}$ Other parameters were optimized such as capillary position inside the nebulizer and the make-up electrolyte level, or height. If CE-ICP-MS migration times were shorter than those found with UV detection, then the make-up electrolyte height was raised which applied hydrostatic pressure to the end of the capillary to neutralize the suction. The optimum make-up electrolyte height for all experiments was $2.0 \mathrm{~cm}$ below the end of the CE capillary.

Adjustment of the capillary position was performed by loosening the PEEK finger-tight fitting and sleeve sealing the capillary into the interface. This releases the seal around the CE capillary and allows manipulation of its position in the back of the nebulizer. The position may be conveniently observed through the glass walls of the nebulizer. The optimum position was determined by observing the CE peak shapes of several lanthanides. Capillary positions of larger than $2 \mathrm{~mm}$ from the inner tube of the nebulizer yielded broad, tailing peak shapes. The best (narrowest) CE peak shapes were observed with the capillary positioned $1 \mathrm{~mm}$ from where the inner nebulizer capillary (liquid uptake tube) narrows to a smaller diameter than the size of the CE capillary. All experiments were performed at this position. Inserting the capillary further into the nebulizer should be avoided because, if the CE capillary touches the tapered entry of the liquid delivery capillary, the nebulizer suction is isolated to the CE capillary. This condition excludes the make-up liquid flow, thus compromising the mechanism that controls nebulizer suction. Also, when the end of the CE capillary contacts the nebulizer, small chips of CE capillary or its polyimide coating might break off, potentially clogging the nebulizer.

\section{Injection procedure}

The source of induced laminar flow within the CE capillary is the nebulizer gas flow. ${ }^{13,16,27,28}$ If laminar flow in the form of suction or back pressure is present during the CE hydrostatic injection step, the amount of sample introduced into the capillary will be affected. This is particularly true when gravity induced CE injection is employed, as the backpressure is lower than a high pressure $\mathrm{CE}$ injection. Otherwise, if laminar flow is properly balanced by the design of the interface, then the CE injection volume will be unaffected. Thus it was necessary to determine whether turning off the nebulizer gas during the $\mathrm{CE}$ 


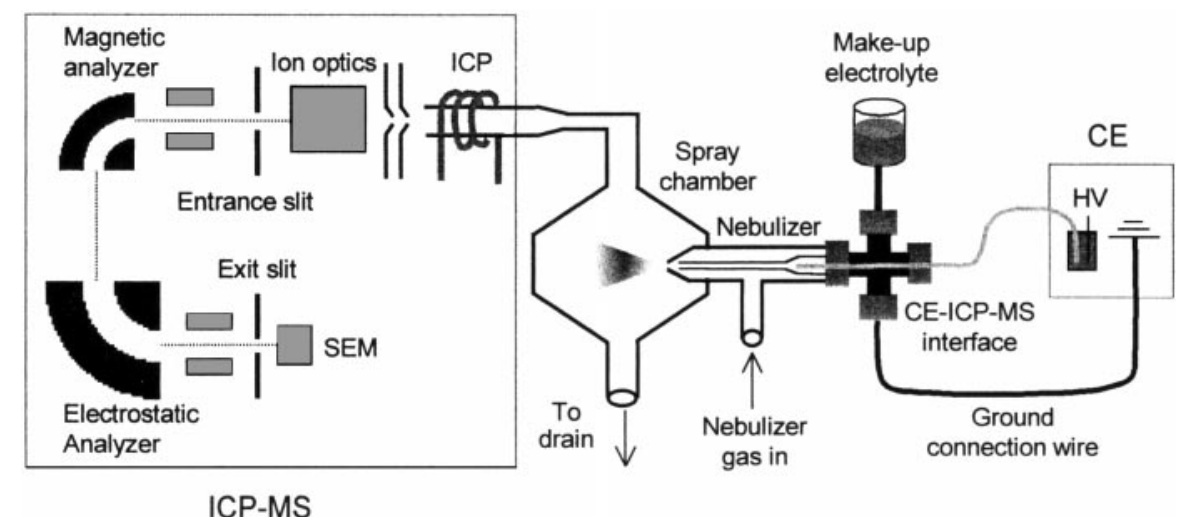

Fig. 1 CE-ICP-MS schematic with Cinnabar small volume cyclonic spray chamber, MicroMist nebulizer, platinum CE ground electrode, make-up electrolyte reservoir, 4 way PEEK union and finger tight fittings.

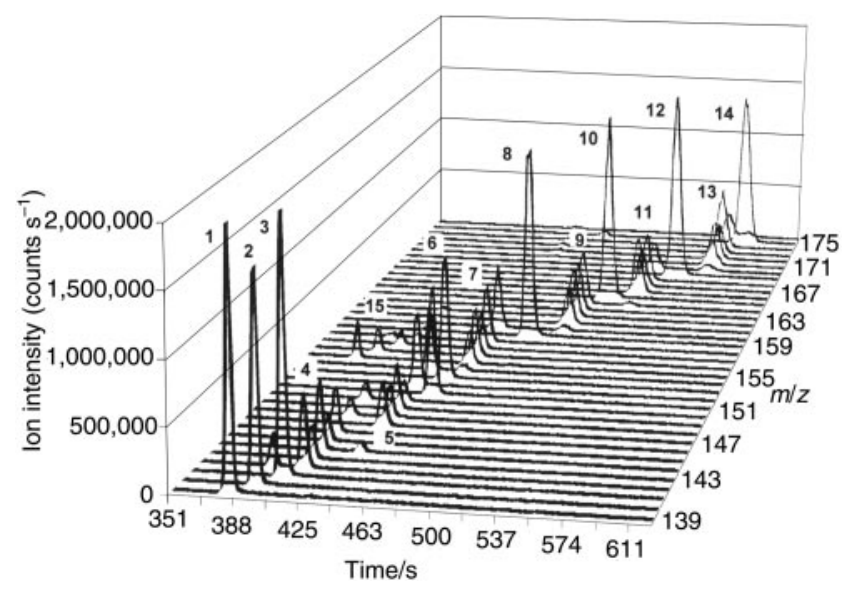

Fig. 2 CE-ICP-MS electropherogram of 14 lanthanides with natural isotope abundances. $\left(0.8 \mu \mathrm{g} \mathrm{ml}{ }^{-1}\right.$ injection. $)(1){ }^{139} \mathrm{La}^{+}(2){ }^{140} \mathrm{Ce}^{+}$(3) ${ }^{141} \mathrm{Pr}^{+}$(4) $\mathrm{Nd}^{+}$isotopes (5) $\mathrm{Sm}^{+}$isotopes (6) $\mathrm{Eu}^{+}(7) \mathrm{Gd}^{+}(8)^{159} \mathrm{~Tb}^{+}$ (9) $\mathrm{Dy}^{+}(10){ }^{165} \mathrm{Ho}^{+}(11) \mathrm{Er}^{+}(12) \mathrm{Tm}^{+}(13) \mathrm{Yb}^{+}(14) \mathrm{Lu}^{+}$(15) oxides of $\mathrm{La}, \mathrm{Ce}$, and Pr.

injection was necessary to achieve reproducible $\mathrm{CE}$ injections for the self-aspirating interface. A calibrated needle valve and an on/off switching valve were installed on the nebulizer gas line to slowly turn the nebulizer gas off during injections, and then on after injection was complete. Manually turning the nebulizer gas on and off must be done carefully to avoid extinguishing the plasma. Four injections of a $1 \mu \mathrm{g} \mathrm{ml}^{-1}$ standard were performed using this procedure and the $\mathrm{Tb}$ peak area results were compared to four injections made while leaving the nebulizer gas on during injection. The average peak areas for the two injection methods were within $1.2 \%$ and the RSD for the eight runs was $3.8 \%$. This suggested that leaving the nebulizer gas flow on during the injection had no influence on the amount of sample injected for each CE run when the interface is optimized to control nebulizer suction.

Two different MicroMist nebulizers were studied, the AR3001-F01 and the AR30-01-F02, with uptake rates of $100 \mu 1 \mathrm{~min}^{-1}$ and $200 \mu 1 \mathrm{~min}^{-1}$ respectively. Using the self aspirating CE-ICP-MS interface, the ion signal intensity with the $100 \mu 1 \mathrm{~min}^{-1}$ nebulizer was half that of the $200 \mu \mathrm{min}^{-1}$ version. This decrease in signal may be due to loss of the analyte to the walls of the spray chamber at the very low liquid flow rates which were present. Adjustment of interface parameters such as the make-up electrolyte vertical height, capillary position, and nebulizer gas flow rate to combat this phenomenon were unsuccessful. Because the performance of the $200 \mu 1 \mathrm{~min}^{-1}$ MicroMist nebulizer was twice as sensitive, more reproducible, displayed good peak shapes, and had migration times very close to those observed with indirect UV

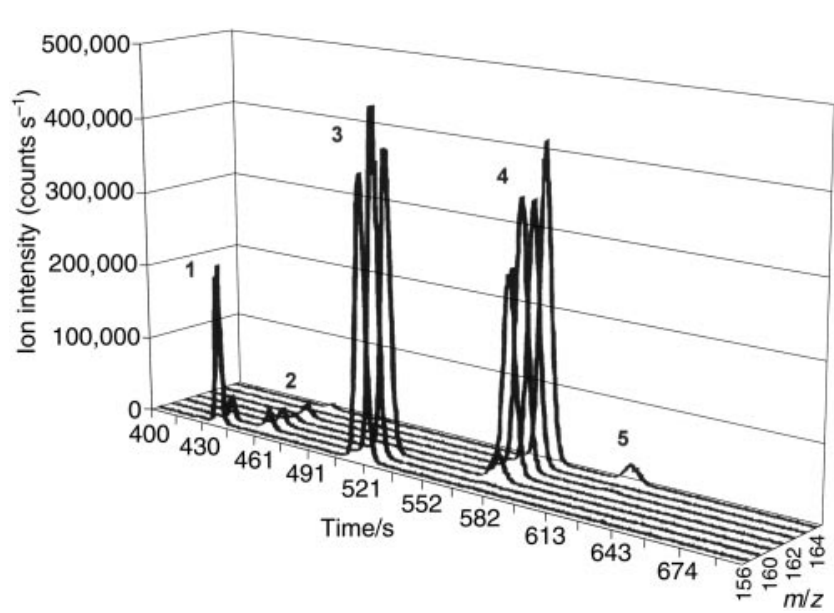

Fig. 3 CE-ICP-MS electropherogram of $m / z 156$ thru 165 showing the isotopes of Dysprosium separated from potential isobaric and polyatomic interferences in a standard sample containing 14 lanthanides with natural isotope abundances $\left(500 \mathrm{ng} \mathrm{ml}^{-1}\right.$ each). (1) Cerium oxides ${ }^{140} \mathrm{CeO}^{+},{ }^{142} \mathrm{CeO}^{+}$(2) Neodymium oxides ${ }^{142} \mathrm{NdO}^{+},{ }^{144} \mathrm{NdO}^{+}$, ${ }^{145} \mathrm{NdO}^{+},{ }^{146} \mathrm{NdO}^{+},{ }^{148} \mathrm{NdO}^{+}$(3) Gadolinium isotopes ${ }^{156} \mathrm{Gd}^{+}$, ${ }^{158} \mathrm{Gd}^{+},{ }^{160} \mathrm{Gd}^{+}$(4) Dysprosium isotopes ${ }^{156} \mathrm{Dy}^{+},{ }^{158} \mathrm{Dy}^{+},{ }^{160} \mathrm{Dy}^{+}$, ${ }^{162} \mathrm{Dy}^{+},{ }^{163} \mathrm{Dy}^{+},{ }^{164} \mathrm{Dy}^{+}$(5) ${ }^{164} \mathrm{Er}^{+}$.

detection, the $200 \mu 1 \mathrm{~min}^{-1}$ nebulizer was used for all experiments.

A CE-ICP-MS electropherogram of a $800 \mathrm{ng} \mathrm{ml}^{-1}$ standard of 14 lanthanides with natural isotope abundances is shown in Fig. 2. Atomic ions of all lanthanides and polyatomic interferences (oxides) of the first six nuclides are resolved. Also, this electropherogram illustrates the low background signals and high ion intensities characteristic of DF-ICPMS. Fig. 3 illustrates a run where only dysprosium isotopes were monitored in a standard containing a $500 \mathrm{ng} \mathrm{ml}^{-1}$ mixture of all 14 lanthanides with natural isotope ratios. The isolation of the polyatomic and isobaric interferences shows the benefit of the CE separation step prior to the ICP-MS detection. Peak area information for each of the isotopes was used to calculate

Table 4 CE-DF-ICP-MS reproducibility. $\%$ RSD of peak data $(n=5)$ for lanthanides $98 \%$ abundant or higher

\begin{tabular}{lllll}
\hline Isotope & $\begin{array}{l}\text { Peak } \\
\text { area }\end{array}$ & $\begin{array}{l}\text { Peak width } \\
(1 / 2 \text { height })\end{array}$ & $\begin{array}{l}\text { Migration } \\
\text { time }\end{array}$ & $\begin{array}{l}\text { Peak } \\
\text { height }\end{array}$ \\
\hline${ }^{139} \mathrm{La}$ & 3.1 & 5.8 & 0.64 & 8.4 \\
${ }^{141} \mathrm{Pr}$ & 2.6 & 6.7 & 0.60 & 2.9 \\
${ }^{159} \mathrm{~Tb}$ & 3.0 & 7.3 & 0.72 & 3.2 \\
${ }^{165} \mathrm{Ho}$ & 1.5 & 5.4 & 0.82 & 8.3 \\
${ }^{169} \mathrm{Tm}$ & 3.5 & 5.2 & 0.73 & 7.6 \\
${ }^{175} \mathrm{Lu}$ & 2.9 & 3.6 & 0.93 & 3.9 \\
\hline
\end{tabular}


Table 5 Relative abundances of lanthanides with multiple isotopes determined by CE-ICP-MS (natural abundances): $0.8 \mu \mathrm{g} \mathrm{ml}^{-1}$ standard $^{-1}$ injection; \% deviation calculated from raw data

\begin{tabular}{|c|c|c|c|c|c|c|c|}
\hline Isotope & Nature & Experimental & Deviation $(\%)$ & Isotope & Nature & Experimental & Deviation $(\%)$ \\
\hline${ }^{140} \mathrm{Ce}$ & 88.5 & 87.9 & 0.7 & ${ }^{154} \mathrm{Gd}$ & 2.18 & 2.21 & 1.3 \\
\hline${ }^{142} \mathrm{Ce}$ & 11.1 & 11.3 & 1.8 & ${ }^{155} \mathrm{Gd}$ & 14.8 & 14.0 & 5.5 \\
\hline${ }^{142} \mathrm{Nd}$ & 27.1 & 27.0 & $\begin{array}{l}1.0 \\
0.4\end{array}$ & ${ }^{156} \mathrm{Gd}$ & 20.5 & 20.7 & 1.0 \\
\hline${ }^{143} \mathrm{Nd}$ & 12.2 & 12.1 & 1.2 & ${ }^{157} \mathrm{Gd}$ & 15.7 & 16.0 & 1.9 \\
\hline${ }^{144} \mathrm{Nd}$ & 23.8 & 23.5 & 1.1 & ${ }^{158} \mathrm{Gd}$ & 24.8 & 23.9 & 3.7 \\
\hline${ }^{145} \mathrm{Nd}$ & 8.30 & 8.52 & $\begin{array}{l}1.1 \\
2.7\end{array}$ & ${ }^{160} \mathrm{Gd}$ & 21.9 & 22.9 & 4.4 \\
\hline${ }^{146} \mathrm{Nd}$ & $\begin{array}{l}0.50 \\
17.2\end{array}$ & $\begin{array}{l}0.52 \\
16.9\end{array}$ & 1.7 & ${ }^{160}$ Dy & 2.34 & 2.42 & 3.4 \\
\hline${ }^{148} \mathrm{Nd}$ & 5.76 & 5.74 & 0.4 & ${ }^{161}$ Dy & 18.9 & 19.4 & 2.6 \\
\hline${ }^{150} \mathrm{Nd}$ & $\begin{array}{l}5.60 \\
5.64\end{array}$ & $\begin{array}{l}. .44 \\
5.85\end{array}$ & $\begin{array}{l}0.4 \\
3.7\end{array}$ & ${ }^{162} \mathrm{Dy}$ & 25.5 & 25.5 & 0.2 \\
\hline${ }^{144} \mathrm{Sm}$ & 3.10 & 3.20 & 3.2 & ${ }^{163} \mathrm{Dy}$ & 24.9 & 25.1 & 0.7 \\
\hline${ }^{147} \mathrm{Sm}$ & 15.0 & 15.0 & 0.2 & ${ }^{164}$ Dy & 28.2 & 28.8 & 2.1 \\
\hline${ }^{148} \mathrm{Sm}$ & 11.3 & 11.2 & 1.3 & ${ }^{170} \mathrm{Yb}$ & 3.05 & 3.17 & 3.9 \\
\hline${ }^{149} \mathrm{Sm}$ & 13.8 & 14.5 & 4.7 & ${ }^{171} \mathrm{Yb}$ & 14.3 & 14.5 & 1.2 \\
\hline${ }^{150} \mathrm{Sm}$ & 7.40 & 7.76 & 4.8 & ${ }^{172} \mathrm{Yb}$ & 21.9 & 21.0 & 4.1 \\
\hline${ }^{152} \mathrm{Sm}$ & 26.7 & 25.9 & $\begin{array}{l}4.0 \\
2.9\end{array}$ & ${ }^{173} \mathrm{Yb}$ & 16.1 & 16.1 & 0.1 \\
\hline${ }^{154} \mathrm{Sm}$ & 22.7 & 22.4 & 1.4 & ${ }^{174} \mathrm{Yb}$ & 31.8 & 30.8 & 3.1 \\
\hline${ }^{151} \mathrm{Eu}$ & 47.8 & 47.9 & 0.3 & ${ }^{176} \mathrm{Yb}$ & 12.7 & 13.2 & $\begin{array}{l}3.1 \\
3.9\end{array}$ \\
\hline \multirow[t]{2}{*}{${ }^{153} \mathrm{Eu}$} & $\begin{array}{l}41.0 \\
52.2\end{array}$ & 52.1 & 0.3 & ${ }^{175} \mathrm{Lu}$ & 97.4 & $\begin{array}{l}15.2 \\
96.3\end{array}$ & $\begin{array}{l}3.9 \\
1.1\end{array}$ \\
\hline & & & & ${ }^{176} \mathrm{Lu}$ & 2.59 & 2.67 & $\begin{array}{l}1.1 \\
3.1\end{array}$ \\
\hline
\end{tabular}

limits of detection (LOD) for the CE-DF-ICP-MS method. Table 3 shows the results for the most abundant isotopes, ranging from $0.7 \mathrm{ng} \mathrm{m}^{-1}$ to $3.9 \mathrm{ng} \mathrm{ml}^{-1}$. The LOD was calcualted as three times the standard deviation of the blank divided by the slope of the calibration curve. A direct comparison to a similar CE-quadrupole ICP-MS system (VG Elemental, PQII STE) shows an improvement in LOD of $\sim 2-$ 10 times for identical separation conditions using a similar interface, small volume single pass spray chamber, and an MCN-100. ${ }^{21}$ For additional comparison, LOD are shown for CE-indirect UV detection, which are nearly three orders of magnitude higher than for the CE-DF-ICP-MS method. Table 4 shows the \%RSD for CE peak areas, peak widths (half height), migration times and peak heights for the most abundant isotopes taken from five replicate injections of a $500 \mathrm{ng} \mathrm{ml}^{-1}$ standard. The peak area and peak height \%RSD values are comparable to values observed in $\mathrm{CE}$ with UV detection. ${ }^{15,21}$ Migration time \%RSD is comparable to values observed for $\mathrm{CE}$ in standard detection mode, indicating the performance of the interface is reproducible and is effective for controlling laminar flow in the capillary during CE runs.

Table 5 shows relative isotope abundances determined from CE-ICP-MS peak area data. The results are compared to table values for lanthanide elements with natural isotope ratios. Peak areas were averaged from five replicate runs of a $500 \mathrm{ng} \mathrm{ml}^{-1}$ standard solution. Nuclides with abundances lower than $1 \%$ were not detectable using this technique and were therefore not calculated. Comparison with natural isotope ratios are within 0.1 to $2 \%$ for nuclides greater than $20 \%$ abundant. Higher deviations are observed for lower abundance isotopes with deviations of $3-5 \%$ from the natural values. Lower abundance isotopes yield much smaller peak areas, and are more difficult

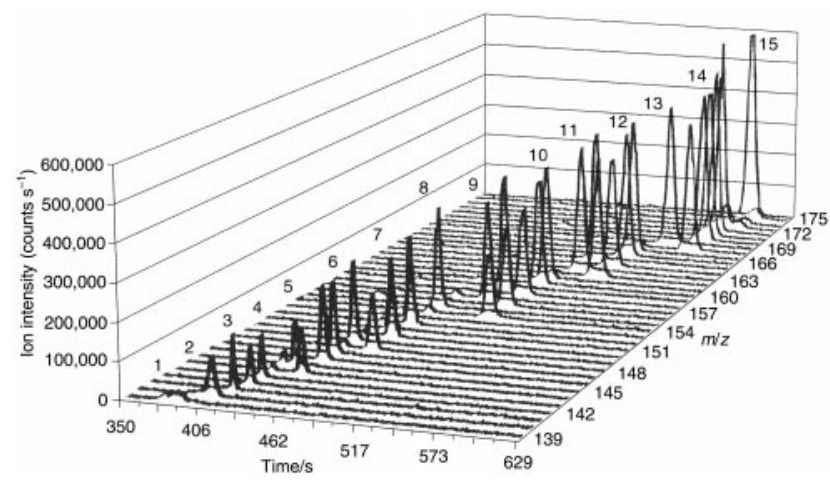

Fig. 4 CE-ICP-MS electropherogram of tantalum target sample. to detect and quantify by CE-ICP-MS. However, this precision was sufficient for the analysis of the irradiated tantalum target sample, and illustrates that the method is applicable to isotopes which are present in relevant concentrations.

An electropherogram of the irradiated tantalum target sample is shown in Fig. 4. The nuclide abundance (peak area) as the mass increases up to ${ }^{180} \mathrm{Ta}$ is characteristic for such samples as the masses in this range are the most abundant spallation products. This also agrees with trends predicted by theoretical calculations. Due to the sample radioactivity, the sample was only analyzed three times on two different days, and the peak data were averaged to produce nuclide abundance values for spallation nuclides in Table 6 . The deviation from the theoretical predictions is shown for experimentally determined values for nuclides found to be more than five percent abundant. Natural isotope ratios are also shown, illustrating the spallation products in the irradiated tantalum target sample, which are not found in natural samples. These nuclide abundances are in agreement with results previously published using HPLC with ICP-MS detection. ${ }^{3}$ The deviation of theory from the experimental values is typically $20-30 \%$, but the theoretical calculations are in close agreement with the experimental values for $\mathrm{Pr}, \mathrm{Eu}, \mathrm{Tb}$ and $\mathrm{Dy}$. The theoretical calculations were successful in determining which nuclides would be present in the spallation source sample for only four of the lanthanide elements studied. It should be noted that the sample was analyzed 5.3 years after termination of the irradiation of the target material, and the theoretical predictions were made much earlier than the CE-ICP-MS experiments. Therefore, the concentrations in the sample may have changed slightly since the sample was irradiated, and since it was analyzed by Kerl. The radioactivity of the sample could alter the composition of the nuclides. Because the deviations from samples with natural isotope ratios were much smaller, the experimental data may be considered more accurate than the theoretical calculations at the time of analysis.

\section{Conclusions}

Fast CE separation ( $<15 \mathrm{~min}$ ) of all lanthanide elements has been illustrated in standards of natural abundance lanthanides and also in the irradiated tantalum target sample. The small sample amounts of $\approx 35 \mathrm{~nL}$ are beneficial in reducing ICP-MS contamination, especially in the analysis of radioactive samples. The elimination of polyatomic and isobaric ICP-MS interferences was accomplished without the use of high resolution mode and allowed the highest ICP-MS sensitivity. 
Table 6 Nuclide abundances of lanthanides produced via spallation reactions in an irradiated tantalum target as determined by CE-ICPMS. Deviation (\%) from the theoretical of experimental is calculated for nuclides $5 \%$ abundant or higher. Isotope abundances for natural samples are shown for comparison

\begin{tabular}{|c|c|c|c|c|}
\hline \multirow[b]{2}{*}{ Element/nuclide } & \multicolumn{3}{|c|}{ Nuclide abundance $(\%)$} & \multirow[b]{2}{*}{ Deviation $(\%)$} \\
\hline & Nature & Theory & Experimental & \\
\hline \multicolumn{5}{|l|}{ Praseodymium } \\
\hline Neodymium & 100 & 100 & 100 & 0 \\
\hline${ }^{142} \mathrm{Nd}$ & 27.1 & 51.9 & $39.8 \pm 6.1$ & 30.4 \\
\hline${ }^{143} \mathrm{Nd}$ & 12.2 & 41.9 & $40.4 \pm 5.9$ & 3.7 \\
\hline${ }^{144} \mathrm{Nd}$ & 23.8 & 2.6 & $6.0 \pm 5.7$ & 56.7 \\
\hline${ }^{145} \mathrm{Nd}$ & 8.3 & 3.4 & $13.8 \pm 4.0$ & 75.4 \\
\hline${ }^{146} \mathrm{Nd}$ & 17.2 & 0.1 & - & \\
\hline${ }^{148} \mathrm{Nd}$ & 5.8 & - & - & \\
\hline${ }^{150} \mathrm{Nd}$ & 5.6 & - & - & \\
\hline \multicolumn{5}{|l|}{ Promethium } \\
\hline${ }^{145} \operatorname{Pr}$ & 0 & 95 & 100 & 5.0 \\
\hline \multicolumn{5}{|l|}{ Samarium } \\
\hline${ }^{144} \mathrm{Sm}$ & 3.1 & 18.9 & $15.6 \pm 5.9$ & 21.2 \\
\hline${ }^{145} \mathrm{Sm}$ & - & 1.1 & - & \\
\hline${ }^{146} \mathrm{Sm}$ & - & 22.9 & $17.6 \pm 4.9$ & 30.1 \\
\hline${ }^{147} \mathrm{Sm}$ & 15.0 & 25.5 & $28.8 \pm 4.2$ & 11.5 \\
\hline${ }^{148} \mathrm{Sm}$ & 11.3 & 3.5 & 2.9 & \\
\hline${ }^{149} \mathrm{Sm}$ & 13.8 & 28.1 & $32.0 \pm 4.8$ & 12.2 \\
\hline${ }^{150} \mathrm{Sm}$ & 7.4 & - & $<1.2^{-}$ & \\
\hline${ }^{152} \mathrm{Sm}$ & 26.7 & - & $<2.0$ & \\
\hline${ }^{154} \mathrm{Sm}$ & 22.7 & - & - & \\
\hline \multicolumn{5}{|l|}{ Europium } \\
\hline${ }^{151} \mathrm{Eu}$ & 47.8 & 47.2 & $46.2 \pm 4.2$ & 2.2 \\
\hline${ }^{153} \mathrm{Eu}$ & 52.2 & 51.5 & $53.8 \pm 4.0$ & 4.3 \\
\hline \multicolumn{5}{|l|}{ Gadolinium } \\
\hline${ }^{148} \mathrm{Gd}$ & - & 15.8 & $19.4 \pm 2.9$ & 18.6 \\
\hline${ }^{150} \mathrm{Gd}$ & - & 18.3 & $18.8 \pm 1.5$ & 2.7 \\
\hline${ }^{152} \mathrm{Gd}$ & 0.2 & 27.2 & $22.1 \pm 2.6$ & 23.1 \\
\hline${ }^{154} \mathrm{Gd}$ & 2.18 & 2.6 & $<3.4$ & \\
\hline${ }^{155} \mathrm{Gd}$ & 14.8 & 34.4 & $33.4 \pm 2.0$ & 3.0 \\
\hline${ }^{156} \mathrm{Gd}$ & 20.5 & 0.57 & - & \\
\hline${ }^{157} \mathrm{Gd}$ & 15.7 & 0.40 & $<2.7$ & \\
\hline${ }^{158} \mathrm{Gd}$ & 24.8 & - & - & \\
\hline${ }^{160} \mathrm{Gd}$ & 21.9 & - & - & \\
\hline \multicolumn{5}{|l|}{ Terbium } \\
\hline${ }^{157} \mathrm{~Tb}$ & - & 44.8 & $44.7 \pm 1.9$ & 0.2 \\
\hline${ }^{159} \mathrm{~Tb}$ & 100 & 55.1 & $54.5 \pm 1.7$ & 1.1 \\
\hline \multicolumn{5}{|l|}{ Dysprosium } \\
\hline${ }^{154} \mathrm{Dy}$ & - & 14.0 & $14.1 \pm 3.5$ & 0.7 \\
\hline${ }^{156} \mathrm{Dy}$ & 0.05 & 16.4 & $17.1 \pm 3.0$ & 4.1 \\
\hline${ }^{158} \mathrm{Dy}$ & 0.10 & 20.5 & $19.9 \pm 2.6$ & 3.0 \\
\hline${ }^{160}$ Dy & 2.34 & 25.5 & $24.3 \pm 1.9$ & 4.9 \\
\hline${ }^{161} \mathrm{Dy}$ & 18.9 & 22.3 & $24.7 \pm 2.2$ & 9.7 \\
\hline${ }^{162} \mathrm{Dy}$ & 25.5 & 0.37 & $-1-2.2$ & \\
\hline${ }^{163}$ Dy & 24.9 & 0.93 & - & \\
\hline${ }^{164} \mathrm{Dy}$ & 28.2 & 0.05 & - & \\
\hline Holmium & & & & \\
\hline${ }^{163} \mathrm{Ho}$ & - & 36.9 & $47.9 \pm 2.1$ & 23.0 \\
\hline${ }^{165} \mathrm{Ho}$ & 100 & 63.1 & $52.1 \pm 1.9$ & 21.1 \\
\hline Erbium & & & & \\
\hline${ }^{162} \mathrm{Er}$ & 0.14 & 19.3 & $22.9 \pm 2.6$ & 15.7 \\
\hline${ }^{164} \mathrm{Er}$ & 1.61 & 21.9 & $24.0 \pm 1.5$ & 8.8 \\
\hline${ }^{166} \mathrm{Er}$ & 33.6 & 30.0 & $25.9 \pm 1.9$ & 15.8 \\
\hline${ }^{167} \mathrm{Er}$ & 23.0 & 28.7 & $27.2 \pm 2.0$ & 5.5 \\
\hline${ }^{168} \mathrm{Er}$ & 26.8 & - & $-1.2+2.0$ & \\
\hline${ }^{170} \mathrm{Er}$ & 14.9 & - & - & \\
\hline Thulium & & & & \\
\hline${ }^{169} \mathrm{Tm}$ & 100 & 99.7 & 100 & 0.3 \\
\hline Ytterbium & & & & \\
\hline${ }^{168} \mathrm{Yb}$ & 0.13 & 16.8 & $16.3 \pm 1.9$ & 3.1 \\
\hline${ }^{170} \mathrm{Yb}$ & 3.05 & 21.0 & $19.1 \pm 2.0$ & 9.9 \\
\hline${ }^{171} \mathrm{Yb}$ & 14.3 & 24.9 & $19.8 \pm 2.5$ & 25.8 \\
\hline${ }^{172} \mathrm{Yb}$ & 21.9 & 16.4 & $19.9 \pm 1.8$ & 17.6 \\
\hline${ }^{173} \mathrm{Yb}$ & 16.1 & 19.3 & $22.1 \pm 1.6$ & 12.7 \\
\hline${ }^{174} \mathrm{Yb}$ & 31.8 & 1.6 & $<2.8$ & \\
\hline${ }^{176} \mathrm{Yb}$ & 12.7 & 0.034 & - & \\
\hline Lutetium & & & & \\
\hline${ }^{173} \mathrm{Lu}$ & - & 8.1 & 4.3 & \\
\hline${ }^{174} \mathrm{Lu}$ & - & 2.5 & 3.6 & \\
\hline${ }^{175} \mathrm{Lu}$ & 97.4 & 84.5 & $88.5 \pm 2.4$ & 4.5 \\
\hline${ }^{176} \mathrm{Lu}$ & 2.6 & 4.9 & $3.6^{-}$ & \\
\hline
\end{tabular}

The determined relative abundances of lanthanide isotopes with natural abundances were typically within $1-4 \%$. These results show the method is applicable to the sensitive and accurate determination of samples with unknown nuclide abundances, such as the irradiated tantalum target material.

\section{Acknowledgements}

JAD and JAC would like to thank the National Institute of Environmental Health Sciences (NIEHS) for financial support through grant number ES04908. We would also like to acknowledge the financial support of the Zentralabteilung für Chemische Analysen, Forschungszentrum Jülich. Also, thanks to Dr. Rajiv Soman, Dr. U. Breuer, Frau Agnes Wiebecke, K. Van Hecke, and J. Dombovari for assistance in various aspects of this research. Helpful comments by Dr. María Montes Bayón are gratefully acknowledged.

\section{References}

1 G. Erdtmann, Analytical techniques for the determination of spallation products in a tantalum target, Research Center Jülich, Internal Report, 1996.

2 J. S. Becker, W. Kerl and H. J. Dietze, Anal. Chim. Acta, 1999, 387, 145.

3 W. Kerl, J. S. Becker, W. Dannecker and H. J. Dietze, Fresenius J. Anal. Chem., 1998, 362, 433.

4 N. Jakubowski, L. Moens and F. Vanhaecke, Spectrochim. Acta, Part B, 1998, 53, 1739 .

5 L. Moens and N. Jakubowski, Anal. Chem., 1998, 70, 251 A.

6 K. Sutton, R. M. C. Sutton and J. A. Caruso, J. Chromatogr. A, 1997, 789, 85.

7 K. L. Sutton and J. A. Caruso, J. Chromatogr. A, 1999, 856, 243.

8 M. M. Bayón, M. G. Camblor, J. I. G. Alonso and A. Sanz-Medel, J. Anal. At. Spectrom., 1999, 14, 1317.

9 T. De Smaele, T. Moens, L. Sandra and R. Dams, Mikrochim Acta, 1998, 130, 241.

10 J. M. Carey, N. P. Vela and J. A. Caruso, J. Anal. At. Spectrom., $1992,7,1173$

11 E. Blake, M. W. Raynor and D. Cornell, J. Chromatogr. A, 1994 683, 223.

12 J. W. Olesik, J. A. Kinzer and S. V. Olesik, Anal. Chem., 1995, 67, 1.

13 J. A. Kinzer, J. W. Olesik and S. V. Olesik, Anal. Chem., 1996, 68 3250 .

14 K. L. Sutton, C. B'Hymer and J. A. Caruso, J. Anal. At Spectrom., 1998, 13, 885 .

15 V. Majidi and N. J. Miller-Ihli, Analyst, 1998, 123, 803.

16 M. V. Holderbeke, J. Anal. At. Spectrom., 1999, 14, 229.

17 K. A. Taylor, B. L. Sharp, D. J. Lewis and H. M. Crews, J. Anal. At. Spectrom., 1998, 13, 1095.

18 Q. Lu, S. M. Bird and R. M. Barnes, Anal. Chem., 1995, 67, 2949.

19 S. Baker and N. Miller-Ihli, Appl. Spectrosc., 1999, 53, 471.

20 J. A. Day, R. S. Soman, K. L. Sutton and J. A. Caruso, Analyst, 2000, 125, 819.

21 A. Prange and D. Schaumlöffel, J. Anal. At. Spectrom., 1999, 14, 1329.

22 Y. Shi and J. S. Fritz, J. Chromatogr., 1993, 640, 473.

23 F. Foret, S. Fanali, A. Nardi and P. Bocek, Electrophoresis, 1990 11, 780

24 J. M. B. Moreno, J. I. G. Alonso, P. Arbore, G. Nicolaou and L. Koch, J. Anal. At. Spectrom., 1996, 11, 929.

25 G. Küppers, J. Radioanal. Nucl. Chem., 1997, 218, 183.

26 P. Jandik and G. Bonn, Capillary Electrophoresis of Small Molecules and Ions, VCH Publishers, Inc., New York, 1993.

27 V. Majidi and N. J. Miller-Ihli, Analyst, 1998, 123, 809.

28 C. B'Hymer, R. M. C. Sutton, K. L. Sutton and J. A. Caruso, Anal. Commun., 1999, 36, 349. 